Erratum

\title{
Aerosol transmission of severe fever with thrombocytopenia syndrome virus during resuscitation — ERRATUM
}

In the original published article by Moon et $\mathrm{al}^{1}$, author Hyeokjin Lee was missing the equal authorship superscript in the byline due to an error introduced during copyediting. Both Jaeyoung Moon and Hyeokjin Lee are equal authors. This has since been updated in the original published article. The publisher apologizes for the error.

\section{Reference}

1. Moon J, Lee H, Jeon JH, et al. Aerosol transmission of severe fever with thrombocytopenia syndrome virus during resuscitation. Infection Control Hosp Epidemiol 2019;40:238-241. 